\title{
ЭСТЕТИЧЕСКИЕ АСПЕКТЫ В ОРТОПЕДИЧЕСКОЙ СТОМАТОЛОГИИ
}

\section{AESTHETIC ASPECTS IN ORTHOPEDIC DENTISTRY}

\section{S. Vyurkov}

Summary. This article provides basic information about the aesthetic considerations in prosthetic dentistry: problems and ways of their solution. Aesthetic restoration of teeth is not only the use of the latest technologies and modern composite materials, but also real jewelry and high professionalism of the dentist. Therefore, it is so important for a modern orthopedic dentist to have the necessary aesthetic knowledge, artistic taste and skills of a sculptor and artist.

Keywords: dentistry, orthopedics, aesthetics, medicine, orthopedic dentistry.
$\Pi$ овышение культурного и материального уровня современных людей требует полного восстановления функций и внешнего вида человека, нарушенного, с потерей зубов у всех пациентов, независимо от их социального положения, профессии и возраста.

Ортопедическая стоматология добилась больших успехов в сфере диагностики, профилактики, а также лечении заболеваний, которые требуют вмешательства ортопедии. И даже в этом случае, необходимость протезирования не уменьшается, а, к сожалению, растет.

Для того, чтобы добиться положительного эффекта при установке зуба, для начала нужно определить уровни верхних зубов по отношению к губам, этому может помочь лабиометрия - это установление типа и размера губы. Но при этом, более достоверное определение уровней режущих кромок фронтальных зубов относительно верхней и нижней губ и их вестибуло-орального положения возможно с помощью функциональных фонетических тестов (рисунки 1 и 2).

Очень важно, особенно при короткой верхней губе, найти не только расположение режущих кромок передних зубов, но и уровень шеек этих зубов.

В иных случаях, если присутствуют явные показания, целесообразно поместить искусственные зубы в зону «притока» [3].

Очень важным и необходимым моментом при установке зубов является обеспечение эстетически правиль-
Вьюрков Сергей Павлович

Стоматолог-ортопед-терапевт, SPClinic Atyrau; Западно-Казахстанский государственный медицинский университет имени Марата Оспанова uispa82@gmail.com

Аннотация. В данной статье приведена основная информация об эстетических аспектах в ортопедической стоматологии, проблемы и пути их решения. Эстетическая реставрация зубов - это не только использование новейших технологий и современных композитных материалов, но и настоящее ювелирное мастерство и высокий профессионализм стоматолога. Поэтому для современного ортопедического стоматолога так важно иметь необходимые эстетические знания, художественный вкус и навыки скульптора и художника.

Ключевые слова: стоматология, ортопедия, эстетика, медицина, ортопедическая стоматология.

ного и, самое главное, естественного внешнего вида лица человека даже в то время, когда человек смеется или улыбается.

Далее были определены компоненты улыбки:

1. степень оголения зубов при улыбке;

2. средние резцовые линии верхней и нижней зубных дуг;

3. «буккальное пространство» - то есть дистанция между видимым краем последнего зуба и углом рта. [5, 7]; (рисунок 3).

Специфические особенности размещения зубов В «пределах губ», в соответствии с перечисленными элементами, могут быть однозначно утверждены врачом при оценивании прошлых фотографий пациентов.

Для того чтобы наилучшим способом изготовить протезы с эстетической точки зрения, должны быть определены анатомические ориентиры, облегчающие изготовление полноценных протезов для специалиста.

Эстетическая реставрация зуба с помощью фотополимеров требует от стоматолога возможности объективно оценить цвет и форму зуба, выбрав правильные оттенки пломбировочного материала, принимая во внимание свойства как самих композитов, а также твердых тканей зуба $[3,4]$. Строгое следование всем необходимым этапам рабочего процесса, которые регламентируются в инструкциях, поддерживает высокое качество изготовления эстетических конструкций, при негативном исходе могут быть совершены ошибки и осложнения 


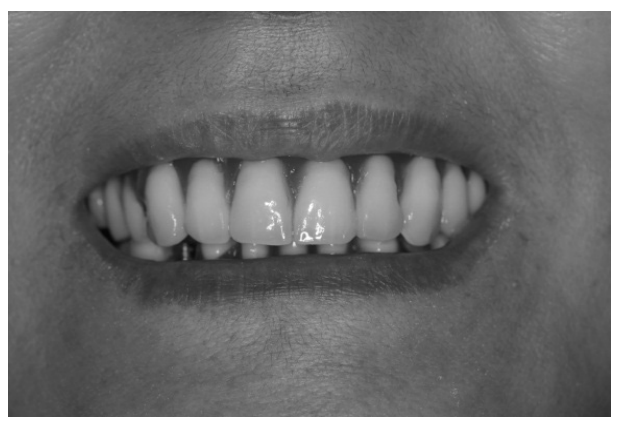

Рис. 1.

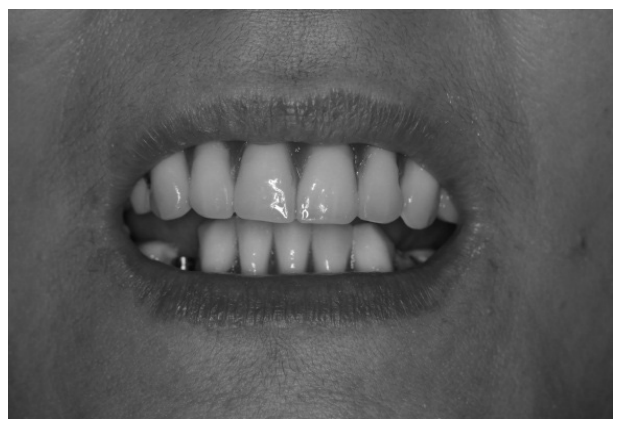

Рис. 2.

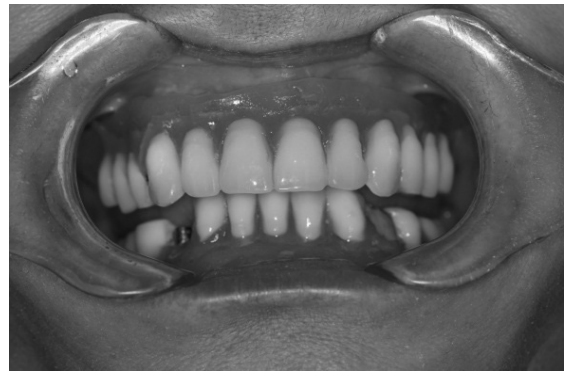

Рис. 3.

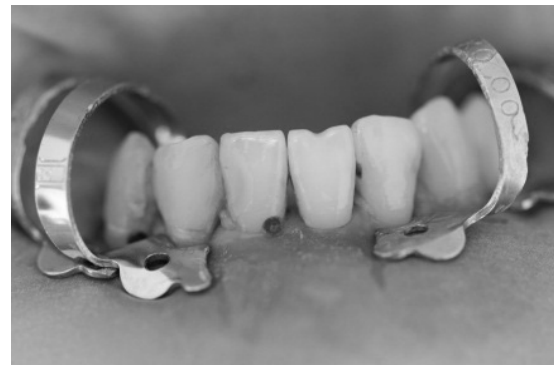

Рис. 4.

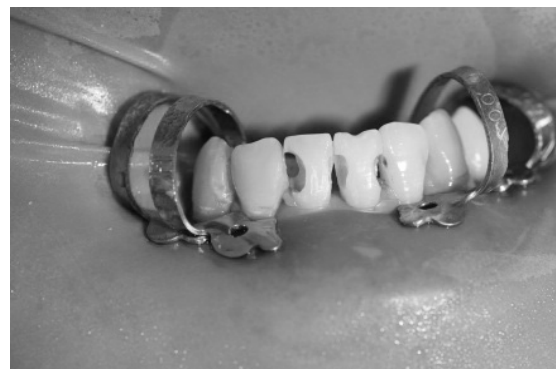

Рис. 5.

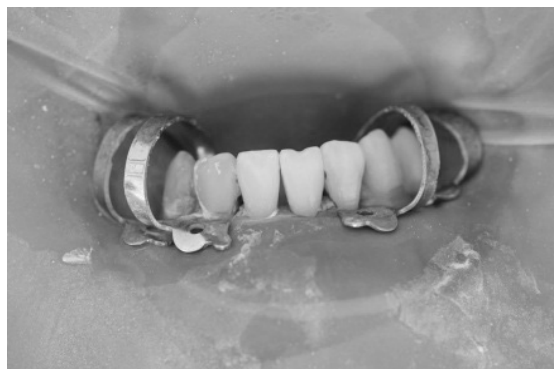

Рис. 6. при их изготовлении, которые появляются как в ближайшем, так и в долгосрочном плане после лечения (рисунки 4,5,6).

Эстетика также является одним из основных современных требований к фиксированным конструкциям. Для достижения этой цели используются различные материалы (металлокерамика, конструкции на основе диоксида циркония или дисиликата лития, прессованная керамика и т.д.). Принципы, лежащие в основе конструкции съемных зубных протезов, дабы достичь необходимого восстановления с учетом эстетического фактора внешнего вида пациента, в достаточной степени применимы к разработке и изготовлению фиксированных зубных протезов (таблица 1). [11]

Важным условием ортопедического вида работ является этап планирования эстетической структуры.
В этом случае восстановленный зуб сравнивается с симметричным зубом по своей геометрической форме, степени контакта между боковыми поверхностями. Одонтоскопия и одонтометрия выполняются с измерением вертикальных и мезиодистальных размеров на симметричных зубах, определяется наличие макрорельефа, определяются цветовые оттенки и степень прозрачности, а также необходимость воссоздать индивидуальные характеристики зуба. Такой подход обеспечивает максимальное соответствие выполненного эстетического дизайна индивидуальным особенностям зуба пациента.

В современности для восстановления целостности зубов используют 2 методики, при которых соблюдается эстетический аспект:

\section{1. Установка микропротезов.}


Таблица 1. Возможности эстетического восстановления зубов

\begin{tabular}{|l|l|}
\hline Возможности эстетического восстановления зубов & Удаление царапин, неровностей и сколов \\
\hline & Изменение цвета зубов(рис 7-8) \\
\hline & Реставрация зубов после травм \\
\hline Устранение щелей между зубами \\
\hline & Эстетическое выравнивание \\
\hline & Изменение ширины, длины и формы зубов \\
\hline
\end{tabular}

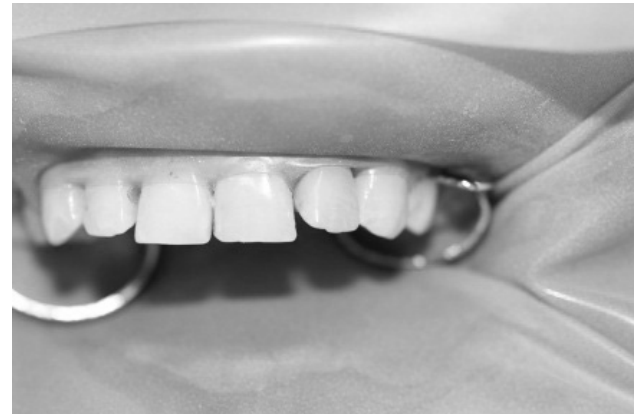

Pис. 7.

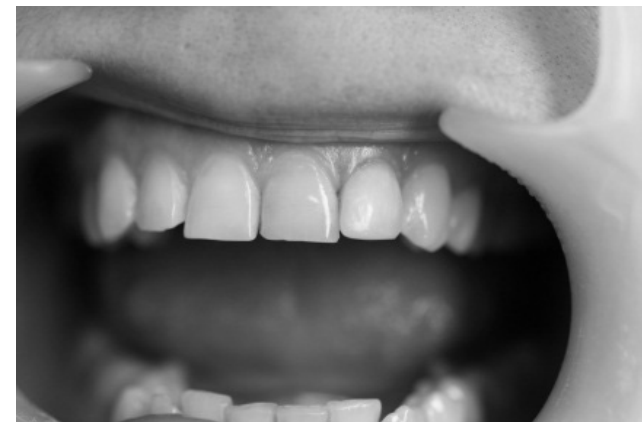

Рис. 8.

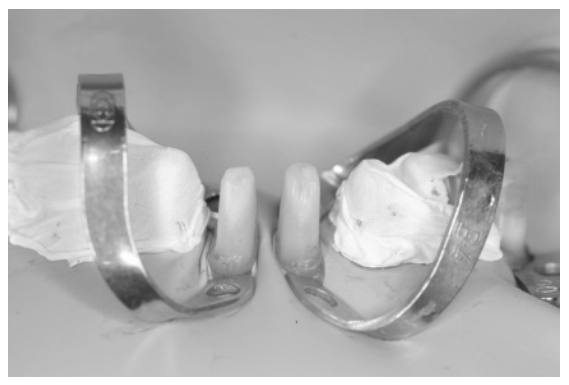

Рис. 9.

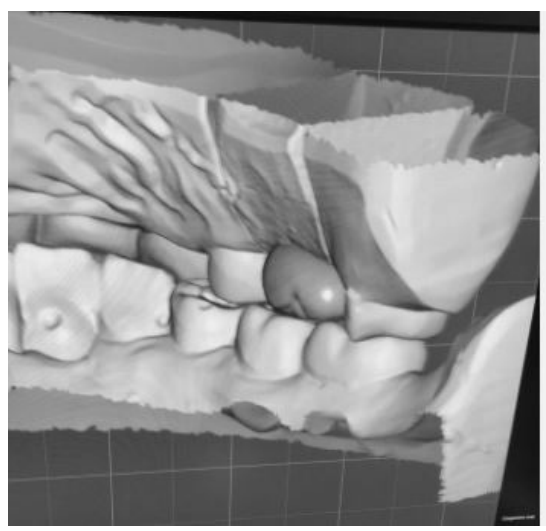

Рис. 12.

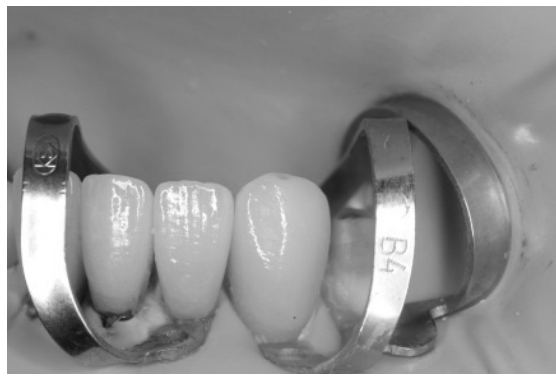

Рис. 10.

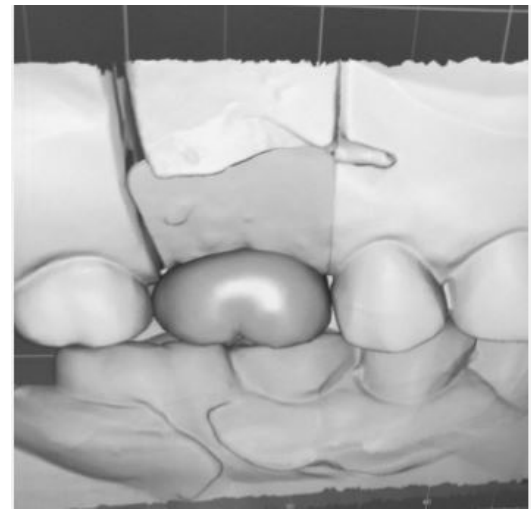

Рис. 13.

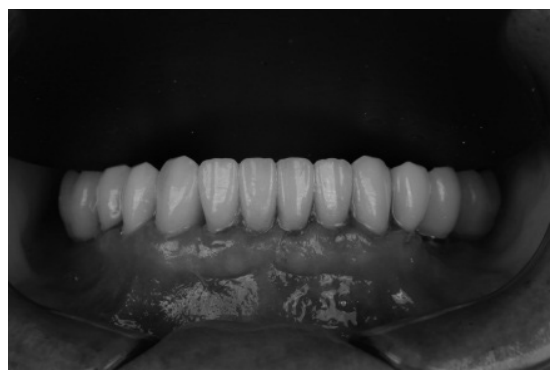

Рис. 11.

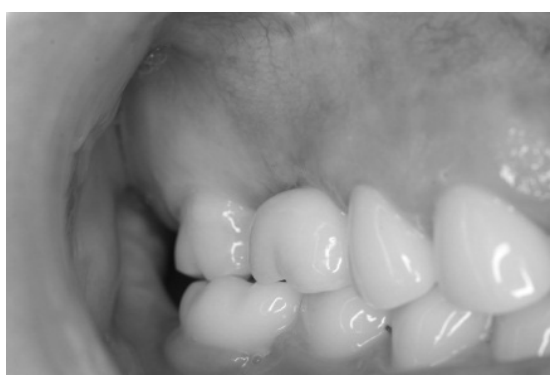

Рис. 14 
Виниры - это керамические накладки, позволяющие привести фронтальную часть зуба в надлежащий вид (рисунки 9, 10, 11).

Сегодня можно смело сказать, что установка виниров устраняет различные дефекты зубного ряда и позволяет получить отличный эстетический эффект. Виниры позволяют создать яркую белую улыбку, которая делает обладателя более уверенным и счастливым.

Виниры представляют собой тонкую пластину толщиной 0,3-0,5 мм. Наклеивается такой микропротез на натуральный зуб с лицевой стороны (там, где зуб соприкасается с губами).

2. Использование композитных материалов для художественной или эстетической реставрации зубов

Зубная эмаль - самая твердая ткань человеческого тела. Однако на этот прочный материал влияют следующие факторы: употребляемая пища и жидкости, механические повреждения и бактерии кариеса. В результате появляются пятна, трещины, сколы, а иногда даже повреждения, влияющие не только на цвет и форму зубов, но и на функцию. Художественная реставрация зубов помогает восстановить привлекательность зубов, их функции и уменьшить дискомфорт пациента.

В целом можно сказать, что художественная реставрация проще (технически и в финансовом плане) и может быть выполнена быстро. Благодаря современным материалам можно добиться отличных результатов, как с функциональной, так и с эстетической точки зрения.

Cerec - это новейшая технология восстановления. Оборудование Cerec сокращает весь длительный про- цесс до двух-трех часов. Использование внутриротового сканера для получения всех данных о зубных рядах занимает несколько минут. Затем информация будет обработана компьютером для создания модели восстановленной коронки с абсолютной точностью и с учетом сотен различных параметров. Это займет несколько минут. После того, как виртуальная коронка будет готова, данные будут переданы на фрезерный агрегат, где установлена керамическая деталь необходимого размера. На шлифовку протеза уходит больше получаса (рисунки $12,13,14)$.

\section{Установка имп^антата}

Современные реставрационные материалы, используемые при установке имплантата, отличаются высокой биосовместимостью с костной тканью, надежной фиксацией и длительным сроком службы. Фактически, это введение нового зрелого органа, включая новый корень и керамическую коронку. Из всех новинок протезов установка имплантатов наиболее физиологична и, к сожалению, очень дорога. Это связано с тем, что мировые производители изготавливают дорогие материалы на высокоточном оборудовании.

В заключение следует отметить, что вершиной искусства моделирования, изготовления и установки искусственных зубов следует считать естественность их внешнего вида в спокойном состоянии, также во время жевательной функции, говорении, смехе, в котором работа демонстрирует навыки врача и зубного техника и, конечно, свое искусство. Следует отметить, что качество ортопедического лечения может быть определено как степенью профессионализма и мастерством врача, так и качеством используемых материалов, а также техникой. [8]

\section{ЛИТЕРАТУРА}

1. Gaurav, Solanki and Renu Solanki Dental Plaque Forming Bacteria's Characterization and Stress Responses: м0ногр. / Gaurav Solanki and Renu Solanki.- M.: LAP Lambert Academic Publishing, 2012. - 136 c.

2. Geetanjali, GandhiAtul Sharma and J.P.S. Kalra Bite — the vertical overlap / Geetanjali Gandhi, Atul Sharma and J.P.S. Kalra. — M.: LAP Lambert Academic Publishing, 2013.- $188 \mathrm{c}$.

3. Ronauk, SinghTapan Singh and Jatinder Pal Singh Maxillofacial Materials — Then And Now / Ronauk Singh, Tapan Singh and Jatinder Pal Singh. — M.: LAP Lambert Academic Publishing, 2014. - 92 c.

4. Vinay, Mohan and Sonal Gupta "Comparision of Antimicrobial Efficacy of Irrigants-An In Vivo Study" / Vinay Mohan and Sonal Gupta.— M.: LAP Lambert Academic Publishing, 2011. - $100 \mathrm{c}$.

5. Агаджанян, Э. Г. Записки доброго стоматолога / Э. Г. Агаджанян.- М.: Омега, 2011. - 176 с.

6. Андреищев, А. Р. Сочетанные зубочелюстно-лицевые аномалии и деформации / А. Р. Андреищев.— М.: ГЭОТАР-Медиа, 2017. - 256 с.

(с) Вьюрков Сергей Павлович ( uispa82@gmail.com ). 